\title{
Prevalence of Dysmenorrhea and its Associated Factors among Adolescent Girls Studying in Technical Schools of Dang, Nepal
}

Nirdesh Baidhya, ${ }^{1}$ Damaru Prasad Paneru ${ }^{1}$

${ }^{1}$ School of Health and Allied Sciences, Faculty of Health Sciences, Pokhara University, Nepal

\begin{abstract}
Introduction: Dysmenorrhea is a gynecological disorder and more often a cause of shame, anxiety and embarrassment among female adolescents. The prevalence of dysmenorrhea worldwide ranges $15.8-89.5 \%$, with higher prevalence rates reported among adolescent female. This study aimed to assess the prevalence of dysmenorrhea and its associated factors among adolescent girls studying in Council for Technical Education and Vocational Training (CTEVT) at Ghorahi Sub-metro Politian Dang, Nepal.
\end{abstract}

Methods: Institutional based cross-sectional analytical study was carried out from February, 2019 to August, 2019 among adolescent girls in technical schools of Dang, Nepal. Self-administered questionnaire was used to collect data from 452 adolescent girls and only 375 adolescent girls were included in the study. Census method was adopted. Data were checked, coded and entered into Epi-data (version 3.1) and transferred to SPSS (version 20) for analysis. Univariate, bivariate and multi variable analyses were carried out. Binary logistic regression model were computed and $\mathrm{P}$ value $<$ 0.05 was considered as significant. All ethical procedures were considered.

Results: The prevalence of dysmenorrhea was 75.2\%, among them half of the respondents experienced moderate pain (50.7\%), followed by mild (26.6\%) and severe (22.7\%). Family history of dysmenorrhea, AOR (95\% CI) $=7.657$ (4.036, $14.528)$, early menarche AOR $(95 \% \mathrm{CI})=15.662(7.583,32.351)$, underweight AOR $(95 \% \mathrm{CI})=0.361(0.149,0.874)$ had statistically significant association with the dysmenorrhea.

Conclusion: Three-quarters of the adolescent girls experienced dysmenorrhea. Dysmenorrhea among adolescent girls is associated with family history, early menarche, whereas underweight was found to be protective factors for the occurrence of dysmenorrhea. All girls entering into menarchhe should be oriented with dysmenorrhea management practices to maintain physical, physiological and psycho- social health.

Keywords: Adolescent girls, dysmenorrhea, severity

\section{INTRODUCTION}

Menstruation is a unique phase of life of a girl. It is a significant stage of puberty. It involves discharging blood and other materials at a regular interval from the inner lining of the uterus and it occurs because of the hormones produced by hypothalamus and pituitary gland located in the brain. ${ }^{1}$ The age of first menstruation varies but most of the studies showed that it occurs generally between the ages of 13 and 15 years. ${ }^{2}$ Menstruation lasts for 3-7 days. ${ }^{3}$ According to World Health Organization (WHO) 'adolescence' is a period between 10 and 19 years. ${ }^{4}$ Dysmenorrhea is a menstrual pain, which is characterized by abdominal pain, backache, stomach cramps, waist pain and thigh pain. ${ }^{5}$

Primary dysmenorrhea is a painful menstruation in women with normal pelvic anatomy, usually beginning during adolescence, whereas painful menstruation with pelvic pathology is defined as secondary dysmenorrhea. ${ }^{6}$ Menstrual pain is common in young age and it affects school attendance and performance along with their social activities and quality of life. Dysmenorrhea affects the daily routine activities of adolescent girls due to prolonged bed rest, missed social activities/commitments, disturbed sleep and decreased appetite. ${ }^{7}$ The study conducted at Chandigarh, India among adolescent girls found that most common symptom experienced by the girls was stomach ache followed by backache and general body pain. ${ }^{8}$

Painful menstruation or dysmenorrhea is a common gynecologic disorder among young females. ${ }^{9}$ The prevalence of dysmenorrhea worldwide ranges $15.8-89.5 \%$, with higher prevalence rates reported in the adolescent girls. ${ }^{10}$ Several studies show that the prevalence of dysmenorrhea was 34\% in Egypt, $64 \%$ in Nigeria and Mexico, $84 \%$ in Thailand $88 \%$ in Turkey and $93 \%$ in Taiwan, $74.5 \%$ in Malaysia, $70 \%$ in Italy, $80 \%$ in Australia, $85 \%$ among Hispanic, and lowest prevalence has been reported in Japan (16\%). ${ }^{11}$ The prevalence of dysmenorrhea is high, ranging approximately between $45 \%$ to $93 \%$ of women of reproductive age, ${ }^{12}$ among them the adolescent girls account

Correspondence: Nirdesh Baidhya, School of Health and Allied Sciences, Pokhara University, E-mail: nirdeshbaidhy2019@gmail.com 
the highest. ${ }^{13}$ Some women (3 to $33 \%$ ) have experiences very severe pain, severe enough that they feel they were deprived of strength or power to carry out routine activities for 1 to 3 days in each menstrual cycle. ${ }^{14}$ Indeed, dysmenorrhea has a high impact on women's lives as restriction in daily activities, low academic performance among adolescents, sleeplessness, mental problems as shame, negative mood, anxiety and depression. ${ }^{15}$

Studies conducted among medical students in Nepal showed that the dysmenorrhea and stress was $67 \% .{ }^{16}$ Similarly, prevalence of dysmenorrhea was $53.8 \%$ among female students of Kathmandu Medical College. ${ }^{17}$ Prevalence of dysmenorrhea among college students was found to be $72.7 \% .^{18}$ The study was carried out to identify the prevalence of dysmenorrhea and its associated factors among adolescent girls in technical schools of Dang, Nepal.

\section{METHODS}

Institutional based cross-sectional analytical study was employed from February, 2019 to August, 2019 among adolescent girls in technical schools of Dang, Nepal. Only adolescent girls between 15 to 19 years, who were unmarried and had menstruation, were included in the study. Self-administered questionnaire contained socio-demographic characteristics, menstrual characteristics were used to collect data from 452 adolescent girls from 11 schools and only 375 adolescent girls participated in the study. Census method was adopted.

Ethical approval was obtained from Institutional Review Committee of Pokhara University. Approval was taken from Ghorahi submetro-politian, education office and technical schools for the study. Written consent was taken from participants as well as from parents for those participants aged below 18 years. Female teacher of respective school was mobilized after orientation for data collection. Questionnaire was distributed by female teacher in the class on the envelop and all the participants was allowed to take home in order to maintain privacy and confidentiality. Questionnaire was pretested among 5\% of adolescent girls of Rapti life care and nursing hospital Tulsipur, Dang and necessary amendment was done. Data collection tool was prepared in English and then translated into Nepali language.

Students self reported the severity of pain on a $0-10$ points numerical pain rating scale and was classified as $(0=$ no pain, $1-3=$ mild pain, $4-6=$ moderate pain, and 7-10 $=$ severe pain $)$.

Data were checked, coded and entered into Epi-data (version 3.1) and transferred to SPSS (version 20) for analysis. Univariate, bivariate and multivariable analyses were carried out. Binary logistic regression model were computed and $\mathrm{P}$ value $<0.05$ was considered as significant.

\section{RESULTS}

\section{Prevalence of dysmenorrhea}

Majority of the adolescent girls under study had experienced dysmenorrhea, that is, 282 out of $375(75.2 \%)$. It was seen that maximum number of adolescent girls 161 out of 375 (42.9\%) experienced dysmenorrhea every months for the last six months, whereas 121 out of 375 (32.3\%) experienced dysmenorrhea irregularly for the last six months as shown in Table 1.

Table 1: Prevalence of dysmenorrhea among technical schools adolescent girls in Dang, Nepal

\begin{tabular}{lll}
\hline Adolescent girls with dysmenorrhea & Frequency & Percentage \\
\hline Every months for the last six months & 161 & 42.9 \\
Irregularly for the last six months & 121 & 32.3 \\
Didn't experienced & 93 & 24.8 \\
\hline
\end{tabular}

\section{Socio-demographic characteristics of participants}

Out of 375 participants, majority of participants were below 18 years $(54.9 \%)$ whereas more than half (56.5\%) were Brahimin/ Chhetri, followed Janajati (23.2\%) and Dalit (13.3\%). The mean age of participants was $(18 \pm 1.187)$ years with minimum age of 15 years and maximum age 19 years. Similarly median monthly income of the participants family was NPR 50,000 with highest monthly income of NPR 1,00,000 and lowest NPR 25,000. Majority of participant's mothers can only read and write, which accounts slightly higher than the quarter $(28.5 \%)$, followed by those, who cannot read and write $(22.1 \%)$ as shown in Table 2 .

Table 2: Socio-demographic characteristics of technical schools adolescent girls in Dang, Nepal

\begin{tabular}{lcc}
\hline Characteristics & Frequency & Percentage \\
\hline Age & & \\
$\quad<18$ years & 206 & 54.9 \\
$\quad \geq 18$ years & 169 & 45.1 \\
Mean S.D $=18 \pm 1.187$, Minimum:15 years, Maximum: 19 years \\
Caste & & \\
Dalit & 50 & 13.3 \\
Janajati & 87 & 23.2 \\
Madeshi & 4 & 1.1 \\
Muslim & 22 & 5.9 \\
Brahimin/Chhetri & 212 & 56.5 \\
Family income & & \\
$\quad<$ NPR 50,000 & 262 & 69.9 \\
$\quad \geq$ NPR 50,000 & 113 & 30.1 \\
Median: NPR 50,000, Minimum: NPR25,000, Maximum: NPR1,00,000 \\
Mothers highest education level & & \\
Cannot read and write & 83 & 22.1 \\
Can read and write & 107 & 28.5 \\
Primary education & 59 & 15.7 \\
Secondary education & 66 & 17.6 \\
Higher secondary or above & 60 & 16.0 \\
\hline
\end{tabular}




\section{BMI distribution among adolescent girls}

Among all the participants, more than half were normal (55.5\%), followed by overweight $(32.3 \%)$, underweight $(10.9 \%)$ and obese $(1.3 \%)$ as shown in Table 3 .

Table 3: BMI distribution among adolescent girls of technical schools adolescent girls in Dang, Nepal

\begin{tabular}{lcc}
\hline BMI & Frequency & Percentage \\
\hline Underweight & 41 & 10.9 \\
Normal & 208 & 55.5 \\
Overweight & 121 & 32.3 \\
Obese & 5 & 1.3 \\
\hline
\end{tabular}

\section{Menstrual characteristics of participants}

Majority of the participants (79.5\%) experienced their first menstruation before reaching 10 years of life whereas, more than half of the respondents $(63.2 \%)$ had their regular menstrual cycle. Majority of participants $(86.6 \%)$ had their normal bleeding during menstruation. Family history of dysmenorrhea was evident among $61.3 \%$ of participants. Prevalence of dysmenorrhea was $75.2 \%$ among participants. Majority of adolescent girls replied lower abdominal pain (87.9\%), followed by back pain $(63.5 \%)$ and headache $(46.8 \%)$ while, than half $(67.4 \%)$ of the adolescent girls replied they felt menstrual pain during menstrual flow, followed by before blood begins to flow $(32.3 \%)$ and less than ten in one $(0.4 \%)$ said after blood has stopped.

Among those, who had dysmenorrhea half of the respondents experienced moderate pain (50.7\%), followed by mild $(26.6 \%)$ and severe (22.7\%) and approximately the three quarter $(74.5 \%)$ of respondents had normal menstrual pain i.e. 1-3 days as shown in Table 4.

Table 4: Menstrual characteristics of participants of technical schools adolescent girls in Dang, Nepal

\begin{tabular}{lll}
\hline Characteristics & Frequency & Percentage \\
\hline Age at menarche $(\mathrm{n}=375)$ & & \\
$<10$ years & 298 & 79.5 \\
$\geq 10$ years & 77 & 20.5
\end{tabular}

Mean S.D $=9.7520 \pm 0.94492$, Minimum: 8 years, Maximum: 12 years
Pattern of menstrual cycle $(n=375)$

\begin{tabular}{|c|c|c|}
\hline Regular & 237 & 63.2 \\
\hline Irregular & 138 & 36.8 \\
\hline \multicolumn{3}{|l|}{ Duration of bleeding $(n=375)$} \\
\hline 1 to 3 days & 83 & 22.1 \\
\hline 4 to 7 days & 242 & 64.5 \\
\hline$>7$ days & 50 & 13.3 \\
\hline \multicolumn{3}{|c|}{ Family history of dysmenorrhea $(n=375)$} \\
\hline Yes & 230 & 61.3 \\
\hline No & 145 & 38.7 \\
\hline \multicolumn{3}{|l|}{ Experience dysmenorrhea $(n=375)$} \\
\hline Yes & 282 & 75.2 \\
\hline No & 93 & 24.8 \\
\hline \multicolumn{3}{|l|}{ Symptoms of dysmenorrhea $(n=282)^{*}$} \\
\hline Lower abdomen pain & 248 & 87.9 \\
\hline Backpain & 179 & 63.5 \\
\hline Headache & 132 & 46.8 \\
\hline Sleeplessness & 124 & 44.0 \\
\hline Fatigue,weakness,irritation & 101 & 35.8 \\
\hline Nausea and vomiting & 88 & 31.2 \\
\hline \multicolumn{3}{|l|}{ Onset of dysmenorrhea $(\mathrm{n}=282)$} \\
\hline Before blood begins to flow & 91 & 32.3 \\
\hline During menstrual flow & 190 & 67.4 \\
\hline After menstrual flow had stopped & 1 & .4 \\
\hline \multicolumn{3}{|l|}{ Severity of dysmenorrhea $(n=282)$} \\
\hline Mild & 75 & 26.6 \\
\hline Moderate & 143 & 50.7 \\
\hline Severe & 64 & 22.7 \\
\hline \multicolumn{3}{|l|}{ Duration of menstrual pain $(\mathrm{n}=282)$} \\
\hline 1-3 days & 210 & 74.5 \\
\hline$>3$ days & 72 & 25.5 \\
\hline
\end{tabular}

\section{Factors associated with dysmenorrhea}

Table 5 shows the association between socio-demographic factors and dysmenorrhea. There is significant association between age and dysmenorrhea $\left(\chi^{2}=7.101, \mathrm{p}=0.008\right)$, Body Mass Index and dysmenorrhea $\left(\chi^{2}=6.861, \mathrm{p}=0.032\right)$.

Table 5: Association between socio-demographic factors and dysmenorrhea

\begin{tabular}{|c|c|c|c|c|c|}
\hline \multirow{2}{*}{ Characteristics } & & \multicolumn{2}{|c|}{ Dysmenorrhea } & \multirow[t]{2}{*}{$\chi^{2}$} & \multirow[t]{2}{*}{ P-value } \\
\hline & & Yes & No & & \\
\hline \multirow[t]{2}{*}{ Age } & $<18$ years & $166(80.6 \%)$ & $40(19.4 \%)$ & 7.101 & $0.008 *$ \\
\hline & $\geq 18$ years & $116(68.6 \%)$ & $53(31.4 \%)$ & & \\
\hline \multirow[t]{2}{*}{ Caste } & Privileged & $163(76.9 \%)$ & $49(23.1 \%)$ & 0.744 & 0.388 \\
\hline & Unprivileged & $119(73 \%)$ & $44(27 \%)$ & & \\
\hline \multirow{2}{*}{ Mothers education } & Literate & $224(76.7 \%)$ & $68(23.3 \%)$ & 1.618 & 0.203 \\
\hline & Illiterate & $58(69.9 \%)$ & $25(30.1 \%)$ & & \\
\hline \multirow[t]{3}{*}{ Body Mass Index } & Underweight & $24(58.5 \%)$ & $17(41.5 \%)$ & 6.861 & $0.032 *$ \\
\hline & Normal & $161(77.4 \%)$ & $47(22.6 \%)$ & & \\
\hline & Overweight/obese & $97(77 \%)$ & $29(23 \%)$ & & \\
\hline
\end{tabular}

* Statistically significant at 95\% level of confidence, $\mathrm{p}$-value $<0.05$ 
Table 6 shows the association between menstrual characteristics and dysmenorrhea. There is significant association between menarche and dysmenorrhea $\left(\chi^{2}=89.196, p=0.000\right)$, pattern of menstrual cycle and dysmenorrhea $\left(\chi^{2}=4.158, \mathrm{p}=0.041\right)$, family history of dysmenorrhea and dysmenorrhea among adolescent girls $\left(\chi^{2}=50.846, \mathrm{p}=0.000\right)$.

Table 6: Association between menstrual characteristics and dysmenorrhea

\begin{tabular}{|c|c|c|c|c|c|}
\hline \multirow{2}{*}{ Characteristics } & & \multicolumn{2}{|c|}{ Dysmenorrhea } & \multirow{2}{*}{$\chi^{2}$} & \multirow{2}{*}{ P-value } \\
\hline & & Yes & No & & \\
\hline \multirow[t]{2}{*}{ Menarche } & $<10$ years & $256(85.9 \%)$ & $42(14.1 \%)$ & 89.196 & $<0.001^{*}$ \\
\hline & $\geq 10$ years & $26(33.8 \%)$ & $51(66.2 \%)$ & & \\
\hline \multirow[t]{2}{*}{ Pattern of menstrual cycle } & Regular & $170(71.7 \%)$ & $67(28.3 \%)$ & 4.158 & $0.041 *$ \\
\hline & Irregular & $112(81.2 \%)$ & $26(18.8 \%)$ & & \\
\hline \multirow[t]{2}{*}{ Duration of bleeding } & Normal & $241(74.2 \%)$ & $84(25.8 \%)$ & 1.430 & 0.232 \\
\hline & Not normal & $41(82 \%)$ & $9(18 \%)$ & & \\
\hline \multirow[t]{2}{*}{ Family history of dysmenorrhea } & Yes & $202(87.8 \%)$ & $28(12.2 \%)$ & 50.846 & $<0.001^{*}$ \\
\hline & No & $80(55.2 \%)$ & $65(44.8)$ & & \\
\hline
\end{tabular}

* Statistically significant at 95\% level of confidence, p-value $<0.05$

On multivariable analysis, Family history of dysmenorrhea, AOR $(95 \% \mathrm{CI})=7.657(4.036,14.528)$, early menarche AOR $(95 \% \mathrm{CI})=15.662(7.583,32.351)$, underweight AOR $(95 \% \mathrm{CI})$

Table 7: Bivariate and multivariate analysis for the factors associated with dysmenorrhea

\begin{tabular}{llrr}
\hline Characteristics & & $\begin{array}{c}\text { Unadjusted odds ratio }(95 \% \\
\text { Confidence Interval) }\end{array}$ & $\begin{array}{c}\text { Adjusted odds ratio (95\% } \\
\text { Confidence Interval) }\end{array}$ \\
\hline Age & $<18$ years & $1.896(1.180,3.046)$ & $0.814(0.437,1.516)$ \\
& $\geq 18$ years & Ref. & Ref. \\
BMI & Overweight/obese & $0.976(0.577,1.654)$ & $0.967(0.502,1.865)$ \\
& Underweight & $0.412(0.204,0.831$ & $0.361(0.149,0.874)^{*}$ \\
Pattern of menstrual cycle & Normal & Ref. & Ref. \\
& Regular & Ref. & $1.689(0.899,3.173)$ \\
Family history of dysmenorrhea & Yes & $1.698(1.018,2.832)$ & $7.657(4.036,14.528)^{*}$ \\
& No & $5.862(3.509,9.792)$ & Ref. \\
Menarche & $<10$ years & Ref. & $15.662(7.583,32.351)^{*}$ \\
& $\geq 10$ years & $11.956(6.734,21.227)$ & Ref. \\
\hline
\end{tabular}

* Statistically significant at 95\% level of confidence, $\mathrm{p}$-value $<0.05$

\section{DISCUSSION}

The prevalence of dysmenorrhea in this study was found to be $75.2 \%$. This was in line with $74.4 \%$ in cross-sectional descriptive study conducted in four secondary schools for girls in Arar city on 344 secondary school students during the academic year 2015 $2016,{ }^{19} 79.67 \%$ in higher secondary schools (Pre-University Colleges) of Gwalior, ${ }^{20} 16 \%$ to $91 \%$ from fifteen primary studies, published between 2002 and 2011, ${ }^{21}$ 79.2\% among high-school female adolescent students in Eastern-Hungary, ${ }^{22} 76.0 \%$ among higher secondary school girls of Imphal West district, Manipur ${ }^{23}$ and $74.5 \%$ among adolescents of the Federal Territory of Kuala Lumpur, Malaysia. ${ }^{24}$

Family history of dysmenorrhea in this was found significantly associated with dysmenorrhea AOR (95\% CI) 7.657 (4.036,
$=0.361(0.149,0.874)$ had statistically significant association with the occurrence of dysmenorrhea as shown in Table 7

Ref. 
inconsistency may be because of the socio-cultural differences of the study groups in pain perception and threshold, life style and age.

Early menarche in this study was found significantly associated with dysmenorrhea AOR (95\% CI) 15.662 (7.583, 32.351). Dysmenorrhea was approximately 16 times higher among those who had their first menstruation at the age before reaching 10 years of life, which was similar with the findings among Nigerian college women. ${ }^{28}$

In this study, a statistically significant association between the presence of dysmenorrhea and underweight was observed AOR (95\% CI) $0.361(0.149,0.874)$. Dysmenorrhea was less likely to have among those who were underweight, which was similar with the findings of systematic review article on prevalence and risk factors of dysmenorrhea ${ }^{21}$. In contrast, dysmenorrhea was found 1.5 times higher in women who were underweight compared with overweight/obese among students at a university in Turkey. ${ }^{27}$

However, no significant difference was observed between dysmenorrhea and pattern of menstrual cycle, AOR $(95 \%$ CI) $1.689(0.899,3.173)$, which was consistent with cross sectional study conducted in seven schools of Pokhara Valley. ${ }^{29}$ However, the systematic review on prevalence and risk factors of dysmenorrhea showed the significant association between presence of dysmenorrhea and irregular cycles. ${ }^{21}$

However, no significant difference was observed between dysmenorrhea and age of participants, AOR $(95 \%$ CI $) 0.814$ $(0.437,1.516)$, but prospective cohort study among Japanese women showed that dysmenorrhea was significantly associated with younger age ${ }^{30}$ and systematic review on prevalence and risk factors of dysmenorrhea confirmed that dysmenorrhea is inversely related to age. ${ }^{21}$ This inconsistency might be because in our study only adolescent girls approximately 15-19 age groups were included and is one time study, less effective results compared to systematic review and prospective study.

\section{CONCLUSION}

The prevalence of dysmenorrhea among adolescent girls in technical schools of Dang, Nepal was high. Dysmenorrhea was more common among adolescent girls with family history of dysmenorrhea, early menarche, whereas underweight was found to be protective factors for the occurrence of dysmenorrhea. All girls entering into menarche should be oriented with dysmenorrhea management practices to maintain physical, physiological and psycho-social health.

\section{ACKNOWLEDGMENT}

We want to forward our special thanks to Institutional Review Committee of Pokhara University Research Centre for providing ethical clearance for the research. Similarly, we are grateful to Prof. Dr. Shyam Thapa and all the participants of the survey taken technical schools who voluntarily provided their valuable information.

\section{REFERENCES}

1. Poureslami M, Osati-Ashtiani F. Assessing knowledge, attitudes, and behavior of adolescent girls in suburban districts of Tehran about dysmenorrhea and menstrual hygiene. Journal of International Women's Studies. 2002; 3: 51-61.

2. Aryeetey R, Ashinyo A, Adjuik M. Age of Menarche among basic level school girls in Madina, Accra. African journal of reproductive health. 2011; 15: 113-21.

3. Lamadah SM, Al Zamil LG. Self Care Practices among Adolescent Females during Dysmenorrhea at Umm Al- Qura University, International Journal of Current Research 2014;6:7137-7144.

4. WHO Programming for adolescent health and development: report of a WHO/UNFPA/UNICEF Study Group on Programming for Adolescent Health. World Health Organization 1999.https://apps.who.int/iris/ handle/10665/42149.

5. Adinma ED and Adinma J. Perceptions and practices on menstruation amongst Nigerian secondary school girls. African journal of reproductive health. 2008; 12: 74-83.

6. Katwal P, Karki NR, Sharma P and Tamrakar SR. Dysmenorrhea and Stress among the Nepalese Medical Students. 2016, p.318-21.

7. Sharma P, Malhotra C, Taneja D, Saha R. Problems related to menstruation amongst adolescent girls. The Indian Journal of Pediatrics. 2008; 75: 125-9.

8. Rani A, Sharma MK and Singh A. Practices and perceptions of adolescent girls regarding the impact of dysmenorrhea on their routine life: a comparative study in the urban, rural, and slum areas of Chandigarh. International journal of adolescent medicine and health. 2016; 28: 3-9.

9. Alsaleem MA. Dysmenorrhea, associated symptoms, and management among students at King Khalid University, Saudi Arabia: An exploratory study. Journal of family medicine and primary care. 2018; 7: 769-74.

10. K Sathish Kumar SK, Hanjabam Sanayaima Devi. 
Dysmenorrhea among higher secondary schoolgirls of Imphal West district, Manipur: A cross-sectional study. Journal of Medical Society. 2016; 30: 38-43.

11. Banikarim C, Chacko MR and Kelder SH. Prevalence and impact of dysmenorrhea on Hispanic female adolescents. Archives of pediatrics \& adolescent medicine. 2000; 154: 1226-9.

12. Patel V, Tanksale V, Sahasrabhojanee M, Gupte S and Nevrekar P. The burden and determinants of dysmenorrhoea: a population-based survey of 2262 women in Goa, India. BJOG: An International Journal of Obstetrics \& Gynaecology. 2006; 113: 453-63.

13. Parker M, Sneddon A, Arbon P. The menstrual disorder of teenagers (MDOT) study: determining typical menstrual patterns and menstrual disturbance in a large population-based study of Australian teenagers. BJOG: An International Journal of Obstetrics \& Gynaecology. 2010; 117: 185-92.

14. Zannoni L, Giorgi M, Spagnolo E, Montanari G, Villa G, Seracchioli R. Dysmenorrhea, Absenteeism from School, and Symptoms Suspicious for Endometriosis in Adolescents. Journal of Pediatric and Adolescent Gynecology. 2014; 27: 258-65.

15. Dorn LD, Negriff S, Huang B, et al. Menstrual symptoms in adolescent girls: association with smoking, depressive symptoms, and anxiety. J Adolesc Health. 2009; 44: 237 43.

16. Katwal P, Karki N, Sharma P, Tamrakar S. Dysmenorrhea and Stress among the Nepalese Medical Students. Kathmandu University medical journal (KUMJ). 2016; 14: 318-21.

17. Karki PK, Rai CR, Kharel SI, Khakurel G. Dysmenorrhea and its association with stress among female students of Kathmandu Medical College. Indian Journal of Basic and Applied Medical Research. 2017; 6:554-8.

18. Anuradha Sutar SP, Nigar Shikalgar, Snehal Ghodey. "Effect of aerobic exercises on primary dysmenorrhoea in college students". Journal of Nursing and Health Science 2016; 5: 20-4

19. Abd El-Mawgod MM, Alshaibany AS and Al-Anazi AM. Epidemiology of dysmenorrhea among secondary-school students in Northern Saudi Arabia. The Journal of the Egyptian Public Health Association. 2016; 91: 115-9.

20. Agarwal AK and Agarwal A. A study of dysmenorrhea during menstruation in adolescent girls. Indian journal of community medicine : official publication of Indian Association of Preventive \& Social Medicine. 2010; 35: 159-64.

21. Ju H, Jones M and Mishra G. The Prevalence and Risk Factors of Dysmenorrhea. Epidemiologic Reviews. 2013; 36: 104-13.

22. Juhasz AG, Vincze G, Krasznai Z, Csorba R and Major T. [Dysmenorrhea in adolescent girls]. Orvosi hetilap. 2005; 146: 27-32.

23. Kumar K Sathish KS, Devi Hanjabam Sanayaima Dysmenorrhea among higher secondary schoolgirls of Imphal West district, Manipur: A cross-sectional study. Journal of Medical Society. 2016; 30: 38-43

24. Wong LP, Khoo EM. Dysmenorrhea in a multiethnic population of adolescent Asian girls. International journal of gynaecology and obstetrics: the official organ of the International Federation of Gynaecology and Obstetrics. 2010; 108: 139-42.

25. Muluneh AA, seyuom Nigussie T, Gebreslasie KZ, Anteneh KT and Kassa ZY. Prevalence and associated factors of dysmenorrhea among secondary and preparatory school students in Debremarkos town, NorthWest Ethiopia. BMC women's health. 2018; 18: 57.

26. Gagua T, Tkeshelashvili B, Gagua D. Primary dysmenorrhea: prevalence in adolescent population of Tbilisi, Georgia and risk factors. Journal of the Turkish German Gynecological Association. 2012; 13: 162-8.

27. Ozerdogan N, Sayiner D, Ayranci U, Unsal A and Giray S. Prevalence and predictors of dysmenorrhea among students at a university in Turkey. International Journal of Gynecology \& Obstetrics. 2009; 107: 39-43.

28. LOTO OM, ADEWUMI TA and ADEWUYA AO. Prevalence and correlates of dysmenorrhea among Nigerian college women. Australian and New Zealand Journal of Obstetrics and Gynaecology. 2008; 48: 442-4.

29. Sharma S, Deuja S, Saha C. Menstrual pattern among adolescent girls of Pokhara Valley: a cross sectional study. BMC women's health. 2016; 16: 74.

30. Ohde S, Tokuda Y, Takahashi O, Yanai H, Hinohara S and Fukui T. Dysmenorrhea among Japanese women. International Journal of Gynecology \& Obstetrics. 2008; 100: 13-7. 